\title{
The Neural Signature of Syntactic Processing
}

\author{
Concha Castillo ${ }^{12}$
}

\begin{abstract}
The aim of this paper is to contribute to the understanding about the processing of syntax in the brain and/or mind of speakers. The focus is specifically on the neural signature of the processing of tense features and of agreement features on the one hand, and on the neural signature of the stage that arguably antecedes the processing of tense features and of agreement features on the other. Neuroimaging studies of the last two decades or so have come to establish that parts of the left inferior frontal gyrus (LIFG) are responsible for syntactic computing proper, and that the left posterior middle/superior temporal gyrus (MTG/STG) appear to be in charge of the projection of phrase structure. Based upon such findings, I defend the convenience of establishing specific goals or tasks that can contribute to their refinement, and that can lead to the acknowledgment of the topography and timing of neural activity at the very first stages of the processing of a sentence.

Keywords: activation of frontal areas (LIFG) vs. temporo-parietal areas (MTG/STG), potential fMRi and MEG experiments, tense features, agreement features, TP-sequences vs. non-TP sequences, phrasal projection vs. feature processing.
\end{abstract}

Contents. 1. Introduction. 2. A Proposal for the Analysis of Tense Features and Agreement Features. 2.1. Feature Valuation in Linguistic Theory. 2.2. The Present Proposal: Justification of (2a). 2.3. The Present Proposal: Justification of (2b). 2.3.1. Linguistic Explanation: the Neural Correlate of V-to-T Movement. 3. A Proposal for the Analysis of Neural Activation Prior to the Processing of Tense Features and Agreement Features. 4. Summary of the Discussion.

How to cite this article: Castillo, C. (2017) The Neural Signature of Syntactic Processing, in Complutense Journal of English Studies 25, 27-47.

\section{Introduction}

Syntax is the core component of natural language according to generative theory, and getting to know how syntactic computation possibly operates in the brain and/or mind of speakers has been in the very last decades, and will purportedly continue to be, a highly sought-for goal within such fields as neurolinguistics, neu-

1 Dpto. Filología Inglesa, Francesa y Alemana, Universidad de Málaga (Spain)

E-mail: eccastillo@uma.es

2 I would like to thank two anonymous reviewers to Complutense Journal of English Studies for their comments and suggestions. All remaining errors are my responsibility. 
ropsychology, or neuroscience in general. ${ }^{3}$ The present paper aims to contribute a line of research that deepens into the findings of the neuroimaging literature of the last ten to fifteen years about the processing of syntax in the brain/mind of speakers, specifically those findings that are or can be directed at identifying the computing process of the initial stages of a sentence.

There is general consensus within the neuroimaging literature as based on such techniques as functional magnetic resonance imaging (fMRi) or magnetoencephalography (MEG) that parts of the left inferior frontal gyrus (LIFG) constitute a core area of syntactic computation, which computation is incidentally further put in connection very frequently with explanations provided by afore-mentioned generative syntactic theory-see e.g. Opitz and Friederici 2004, Petersson and Hagoort 2012, or the review work of Friederici $2012 .^{4}$ Central domains with which LIFG has been associated in the literature are e.g. wh-movement, that is a process by means of which the canonical or neutral order of a sequence is clearly disrupted by the displacement of a wh-constituent to initial position (see (1a)), or the processing of finite verbs, which is also crucially analyzed within the generative framework as a relation that must be established between two elements, the verbal root on the one hand, and so-called tense features and agreement features on the other. See the labelled bracketing notation in (1a) and the labelled bracketing notation in (1a') for an illustration of wh-movement, and the labelled bracketing notation in (1 $\left.\mathrm{b}^{\prime}\right)$ for an illustration of the position where a verbal root belongs originally in the process of construction of a sentence, and likewise the position that a feature as [+present $]$ is assumed to occupy. ${ }^{5}$ As is widely known, tree-diagrams are a kind of metaphor innovated by the generative model in the first half of last century in order to represent syntax, or more properly syntactic space. From the current perspective of minimalist syntax (within the generative model), the relation or connection between the specific nodes or positions as signalled on the trees $\left(1 a^{\prime}\right)$ and $\left(1 b^{\prime}\right)$ below is understood as the licensing of some feature: wh-features in the case of $\left(1 \mathrm{a}^{\prime}\right)$ and tense and agreement features as regards $\left(1 b^{\prime}\right)$.

(1) a. [ What ${ }_{o}$ might $\left[\right.$ John buy $t_{0}$ ?] $]$

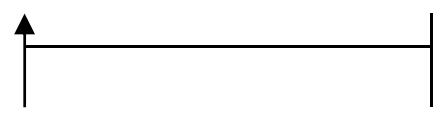

3 The phrase brain/mind is used throughout the text just for convenience: it is therefore not intended to express synonymity between the two terms. As generally agreed, brain is typically understood as a physical organ, whereas mind is usually considered an intangible, abstract construct.

4 As a reviewer points out, LIFG was originally associated, and it still undoubtedly is, with operations relative to word comprehension and production, which means that it is a major area involving semantic and phonological functions. Nonetheless, in the last fifteen years or so, LIFG has also been the focus of many neuroimaging studies of syntax. Although it is fair to say that there are multiple theories of the role that LIFG plays in syntactic processing, the works cited in the main text appear to establish a solid connection between well-known constructs in the field of generative syntactic theory and findings relative to neural implementation. One relevant aspect to clarify is the role of LIFG in syntactic operations realized by subjects as overt tasks (as opposed to covert or silent tasks) in corresponding neuroimaging experiments.

5 As shown in $\left(1 \mathrm{a}^{\prime}\right)$, the element what shares the same index as the trace in the position of complement or sister to $\mathrm{V}$ (i.e., what $t_{0}-t_{0}$ ), which means that wh-movement from within the VP up into the complementizer phrase has applied. As for $\left(1 \mathrm{~b}, \mathrm{~b}^{\prime}\right)$, the verbal root moves initially from $\mathrm{V}$ into $v$, and then a connection is established between the verb in $v$ and the node $\mathrm{T}$, where the relevant feature [+present] is located. The cited connection is indicated with the arrows. 
a.' $\quad\left[\mathrm{CPWhat}_{\mathrm{o}}\left[\mathrm{Cmight}_{\mathrm{m}}\left[\mathrm{TP}_{\mathrm{COhn}}\left[\mathrm{T}_{\mathrm{m}}\left[\mathrm{vpt}_{\mathrm{s}}\left[\mathrm{v}_{\mathrm{v}} \mathrm{buy}_{\mathrm{v}}\left[\mathrm{vpt}_{\mathrm{v}} \mathrm{t}_{\mathrm{o}}\right]\right]\right]\right]\right]\right]\right]$

b. John smile-s / John call-s Mary / He paint-ed the wall

b.' $\quad\left[\mathrm{TPJohn}_{\mathrm{s}}\left[\mathrm{T}^{+}\right.\right.$pres. $\left.\left.\left[\mathrm{vPt}_{\mathrm{s}}\left[\mathrm{vsmile}_{\mathrm{v}}\left[\mathrm{vpt}_{\mathrm{v}}\right]\right]\right]\right]\right]$

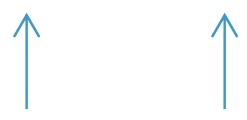

LIFG has thus been identified as a relevant area where the licensing of whelements or of finite verbs applies, which licensing is analyzed in standard generative accounts as the licensing of features. In an important way, an area such as the left posterior middle and superior temporal gyrus (MTG/STG) has been associated with the building up or projection of phrases that arguably applies before the cited syntactic activity in LIFG (for instance, the very projection of the VP in $\left(1 b^{\prime}\right)$, which must antecede the licensing of the tense features and agreement features on the part of the verb). This paper focuses on two of the above-mentioned domains, namely the licensing of tense features and agreement features on the one hand, and the phrase building mechanism that applies before the cited licensing of tense features and agreement features on the other, and proposes a line of investigation that can contribute to identifying the computation of such elements and mechanisms, which must presumably apply at the initial stages of the overall computation process of a sentence.

As suggested above, the neuroimaging findings in the literature as regards the processing of syntax and morphology are formidable, since specific parts within LIFG in charge of the processing of tense and agreement features appear to have been identified already, or also important aspects of the division of labour between the frontal areas on the one hand and temporo-parietal areas on the other appear likewise to have been detected, as suggested immediately above: however, such findings need to be made more precise, and the novel view contributed by this paper is that the proposals presented here focus on verifying whether the neural activity that has already been detected actually corresponds to the computing process of a sentence, and exactly to what stage within such computing process. In other words, identifying in as precise a way as possible the computing process of a sentence is a first goal in the context of the neurobiology of language, and isolating the neural signature of tense features and of agreement features, and the distinction between such a signature and the signature of the building process of the phrases (VP and TP) that arguably antedates it is a crucial portion of that goal, according to (generative) linguistic theory. Given that the proposal in this paper is to make it possible for relevant research to discern between very sensitive phenomena, that is phenomena that apply at very small syntactic spaces (actually the ones that figure in between V (or VP) and $\mathrm{T}$ in the notation (1 $\mathrm{b}^{\prime}$ ) above) then the sentences to be proposed as linguistic stimuli for the participants in the corresponding fMRi or MEG experiments must be as small as possible: simple sentences of the affirmative declarative type containing the smallest number possible of constituents. A sample 
of such stimuli is found in the Appendixes at the end of the paper, as specified immediately below.

The organization of the paper is as follows. Sections 2-2.3.1 are dedicated to the proposal for the analysis of tense features and agreement features, and Section 3 focuses on the proposal for the analysis of the neural activity that is prior to the cited processing of tense features and agreement features, namely the building up of VP, and also of TP. Section 4 is a summary of the discussion and, after this, Appendixes I-III illustrate a sample of the paradigm of stimuli that would correspond to the tasks or goals of each proposal.

I would like to highlight the fact that the proposals in this paper originate from background in theoretical linguistics (my own research is in the field of syntactic generative theory, both synchronic and diachronic) and from the acknowledgment of the need expressed in the neuroimaging literature in general that the regions within the LIFG on the one hand, and those in the temporo-parietal area on the other, be characterised as closely as possible as regards the processing of syntax.

\section{A Proposal for the Analysis of Tense Features and Agreement Features}

Tense features and agreement features can be roughly characterized as affixes that are appended to a verbal root and whose interpretation is identified as [+/-present], and [person] and/or [number], respectively. Within the neurocognitive literature, the processing of verbs inflected for tense and agreement has actually been the target of manifold studies, as suggested in Section 1. Aside from those works that focus on the contrast between e.g. regular forms vs. irregular forms, the ones that matter most for the present proposal are those that appear to have shown that the neural signature of morphological agreement on a verb is distinct from that on e.g. a nominal since, according to generativist linguistic theory, and as will be described in Section 2.1, an important part of the construction of a sentence consists in that verbs process one of these features, namely agreement features, basing on the agreement features that nominals own themselves in an inherent way, whereas nominals, as just said, are the natural bearers of such features, which are present on the nominal itself from the beginning of sentence construction: more technically, nominals have valued and interpretable agreement features.

Now, such works as Finocchiaro et al. (2010), Kielar et al. (2011), or Shapiro et al. (2012), and also Yokohama et al. (2006) or Sahin et al. (2009), reach the general conclusion that so-called Broca's area-that is, BA44 and BA45 in LIFG-is clearly more strongly activated in the case of verbs than with nouns. On the other hand, BA44 is specifically associated in current neurocognitive literature in general with the area where complex syntactic computing or complex morphological processes apply (see e.g. the review articles of Friederici $(2011,2012)$, or also van der Lely and Pinker (2014), where complex computing is used to refer to processes that imply overt movement of an element from one position to another, or the suffixation of regular morphology to a root).

The analysis of the processing of tense features and agreement features on verbs in the brain/mind of speakers takes the following form in the present proposal:

(2) Identification of the neural signature of tense features and agreement features in the process of computation of a sentence: 
(a) Verification that the neural correlate of tense features and agreement features as part of the building up of a sentence is distinct from the neural correlate of tense and agreement features as (mere) component elements of a morphological paradigm.

(b) Verification that the neural correlate of tense features is distinct from that of agreement features.

Reference to a distinct neural correlate in both (2a) and (2b) means of course for neural activation to be available or to be stronger at a different timing or in different areas, depending on the element or the mechanism that is being analyzed. The justification that I would like to provide as regards (2a) lies in the fact that, despite the findings in the neuroimaging investigation mentioned above regarding activation of BA44 and/or BA45, it remains undefined whether tense features and agreement features have actually been monitored as part of the processing of a sentence proper, or otherwise as the ratification of a morphological paradigm in the brain/mind of speakers. As for the justification of (2b), this consists in that tense features and agreement features must not only be discriminated from within the overall process of sentence computing, but that they must also be discriminated from each other. According to my own research, which I summarize later in Section 2.3.1, identifying tense features independently of agreement features entails identifying the neural signature of so-called $V$-to-T movement.

In Section 2.1 I provide a description of the linguistic mechanism of feature valuation, and in Sections 2.2 and 2.3 I deal in detail with the proposal in (2).

\subsection{Feature Evaluation in Linguistic Theory}

In order to acknowledge the central role played by tense features and agreement features in the linguistic construct that is the derivation of a sentence, that is the way in which a sentence is built up according to minimalist theory, it is appropriate to begin by saying that tense features and agreement features have traditionally been identified as the head or nucleus I(nflection), which is simplified, later on in the theory, as $\mathrm{T}(\mathrm{ense})$ (let us recall $\left(1 \mathrm{~b}^{\prime}\right)$ ) and which is distinct from the head V (or also the head Aux). Generative theory postulates that syntax is the core component of natural language, that which is in charge of combining words into phrases, and phrases into sentences and/or clauses. The notion of phrase structure building experiences a major development when it acquires full endocentric status in the G(overnment) and B(inding) X'-model of the 1980's (Jackendoff 1977; Chomsky 1981), which comes to analyse sentences and clauses as phrases proper, their head or nucleus being afore-mentioned I(nflection) (or T(ense)). As already observed, the contents of $\mathrm{T}$ is typically considered to be tense features (that is, [+/-present] features) and agreement features (that is, person and/or number features) and one of the hall-marks of generative theory at the time of the GB model is the movement that is argued to take place between V (or Aux) on the one hand, and T on the other in order for the verbal root and tense and agreement features to combine together (so-called V-to-T movement, for which see below in Section 2.3.1). Incidentally, a solid argument provided by GB theory in support of $\mathrm{T}$ as the head of a sentence is for simple sentences (or main clauses) to contain obligatorily a finite verb, that is a verb showing finite $T$. 
After GB theory, within the minimalist period of generative grammar that expands from the early 1990s until today, and that has already meant formidable progress on manifold fronts towards the explanatory capacity of syntactic theory, tense features and agreement features are once more at the centre of a linguistic derivation. More specifically, in the seminal Merge and Agree framework of Chomsky (1995, 2000, 2001, 2004, et seq.) T, V, and the nominal which is to become S(ubject) act as Probes and/or Goals that must have their features licensed against each other, the relevant licensing of tense features and of agreement features being an indispensable part of the interplay between these elements and, consequently, of the overall derivation of the sentence.

Features are characterized according to the properties of valuation and interpretability. These properties are bound together in the widely-known biconditional of Chomsky (2001), which states that a feature is uninterpretable "if and only if it is also an unvalued feature". Nevertheless, Pesetsky and Torrego (2001, 2004, 2007) postulate that one thing is the interpretability of a feature, that is the capacity of a feature to contribute meaning to the lexical item it belongs to (and consequently to the sentence as a whole) and another thing is for a feature to be valued, that is the circumstance according to which the feature in question comes from the Lexicon already specified for a given property. This allows Pesetsky and Torrego to analyze tense features as being interpretable on $\mathrm{T}$ but valued on $\mathrm{V}$, a view that has been generally accepted in the minimalist literature. As for agreement features, Chomsky $(2000,2001)$ and Pesetsky and Torrego $(2001,2004,2007)$ agree in analyzing these as being uninterpretable and unvalued on $\mathrm{T}$ and interpretable and valued on the nominal that is to become $\mathrm{S}\left(\right.$ ubject). ${ }^{6,7}$

The way by means of which features are licensed by the element that is in need of doing so (the Probe) against the element that can provide either valuation or interpretation (the Goal) is Agree. In effect, as mentioned above, the derivation of a sentence proceeds through the operations Merge and Agree, where Merge is the combination of two syntactic units from the Lexicon, and Agree is the relation that is established between a Probe and a Goal. Further, the licensing of features will entail the movement (or internal Merge) of the Goal whenever the Probe has a so-

6 A major difference between Chomsky's framework and Pesetsky and Torrego's framework as regards agreement features is that nominative Case on the S(ubject) nominal is argued by Chomsky to be valued by $\mathrm{S}$ in return for the licensing of agreement features on T, whereas Pesetsky and Torrego postulate that nominative Case is the counterpart of tense features. The issue of Case on a nominal is nevertheless not relevant for the present discussion.

7 Though this is not an aspect that can condition in any way the proposal put forward in this paper as regards the monitoring of tense features and agreement features, I would like to note that, in Castillo (2016), I defend that it is $v / \mathrm{V}$ properly speaking, rather than $\mathrm{T}$, that must license agreement features against $\mathrm{S}$, a hypothesis that is reminiscent in a way of the original approach proposed by Pollock (1989) according to which agreement features are licensed in a lower position on the tree than tense features. Based upon the big homogeneity of agreement features through the various tenses in many different kinds of languages - that is languages showing rich or poor agreement morphology, and/or languages showing rich or poor tense features - and based also on the fact that agreement features are interpretable on $\mathrm{S}$ itself, and not on any other element, I propose that $v / \mathrm{V}$ values the cited agreement features against $\mathrm{S}$, though of course the full process of verbal inflection licensing is not complete until after tense features (against T) have been valued. 
called EPP feature or property. In case there is no such EPP feature, then Agree will take place without movement. ${ }^{8}$

Also in regard to the interplay between $\mathrm{T}, \mathrm{V}$, and $\mathrm{S}$, it is relevant to observe that Chomsky $(2000,2001)$ suggests the idea that $T$, aside from having agreement features to value against $\mathrm{S}$, also has a $D$-feature to value, which provokes the movement of the constituent fulfilling the role of subject of predication into the Spec position of T. This hypothesis or idea would make it possible to dissociate the constituent bearing valued interpretable agreement features-which is necessarily a nominal - from the constituent that eventually occupies Spec,T, which is typically but not necessarily a nominal: let us think of English structures with dummy there in initial position (There is a cat on the roof) or a locative PP in initial position (Between John and Mary sat the child). In these, the nominal bearing interpretable agreement features (namely, a cat and the child, respectively) is of course not in subject position.

\subsection{The Present Proposal: Justification of (2a)}

The goal in (2a) that is proposed in the present paper for potential neuroimaging research to take into consideration centres around the impact of the relation between syntax and morphology as regards the analysis of tense features and of agreement features. Now, generative theory has generally considered tense and agreement features to have an abstract syntactic status (let us recall the brief characterization of these in Section 2.1 immediately above as the contents of the node $\mathrm{I}$, or rather $\mathrm{T}$ ) which is independent of their morphological or morphophonological realization. The same, the idea of morphological paradigms independent of syntax, that is of listings of words in the Lexicon that share a common root to which different affixes can be appended, is a completely valid one. Nonetheless, the analysis of the relation between syntax and morphology is of course indispensable for the understanding of language, and this both from the point of view of neuroscientific research and from the point of view of the linguistic community.

In effect, from the perspective of linguistic theory, it is two opposing views that can be distinguished: one that argues that morphology is part of core or narrow syntax, and another that defends the idea that morphology is to be accounted for separately, and typically after, narrow syntax. The first view, which is the one that I adopt in my own research generally speaking within syntactic theory, sustains that morphological richness can indeed result in a more complex syntactic derivation, since morphological richness can entail either a higher number of (syntactic) features to license, or it can otherwise entail the movement of some element in the course of the derivation. Such a view or treatment of morphology is one that is at the base of the prospective goal in (2b), and it is dealt with in Section 2.3 below.

For the specific proposal in (2a), the notion of morphology that is relevant is that of lists or paradigms of words - in the case at hand, of verbs inflected for tense

8 The presence or absence of the cited EPP feature or property comes to replace within the minimalist framework the GB notion of strong vs. weak feature (the former being the kind of feature that triggers movement, as opposed to the latter). 
and agreement - and this is because (2a) invokes the need that neuroscientific research be aware that such verbs (that is, verb inflected for tense and agreement) are being monitored not as a kind of morphological exercise but as component parts of a sentence. That is, the point that I would like to make is that, with an aim at identifying the neural signature of tense features and agreement features within the computation of a sentence, it is necessary to ensure that what is being tested is when and where such processing takes place in the course of the derivation of a sentence, and not as part of a paradigm, in the present or in the past, and typically ranging from first person singular to third person plural.

In order to achieve this, I would like to propose that neuroimaging experiments in question make use of a distinct presentation of linguistic stimuli: on the one hand, linguistic stimuli will be presented as the typical lists that we identify from all kinds of textbooks as verbal paradigms, and on the other hand they will be presented as sentences proper, that is one-line sentence per screen, with a period following the last word. I should thus like to complement the goal in (2a) as in (2a').

(2) a. Verification that the neural correlate of tense features and agreement features as part of the building up of a sentence is distinct from the neural correlate of tense and agreement features as (mere) component elements of a morphological paradigm.

a.' Relevant methodology: Presentation of stimuli in the form of morphological paradigms vs. sentences proper.

The reader is referred to Appendix I at the end of the paper for a sample of relevant stimuli corresponding to this goal.

\subsection{The Present Proposal: Justification of (2b)}

The identification of the specific neural activation that corresponds to tense features and to agreement features entails on the present proposal not only discriminating between the processing of gross morphological paradigms and proper sentences (as stated in ( $2 \mathrm{a}$ ) above), but also discriminating, within the context of proper sentences, between one type of feature (tense features) and another (agreement features). ( $2 b)$ is repeated below with the same numeration and immediately below, as $\left(2 b^{\prime}\right)$, I advance the way in which this can be achieved.

(2) b. Verification that the neural correlate of tense features is distinct from that of agreement features.

b.' Relevant methodology: Contrastive analysis of three languages that behave differently in the licensing of tense features and agreement features.

Now, proposing to monitor in corresponding fMRi or MEG experiments speakers of languages which differ as regards tense features and agreement features is not a trivial proposal, since the relevant difference or distinction is not one that could be characterized as immediately observable. That is, it is just not enough to compare a language like e.g. English, with poor verbal inflection in general, with a language like e.g. Spanish, with rich verbal inflection in general, since there are languages like German, which have the appearance of richly inflected languages, but which 
pattern like English as regards verbal morpho-syntax in the way to be specified immediately below.

In effect, in Castillo (2014, 2016), I argue that a specific type of morphological richness of tense features does provoke for the verb to be linearized more to the left or, the same, higher in some languages as compared to others (so-called V-to-T movement), and this independently of richness of agreement features, which must be taken to mean that tense features can be isolated from agreement features, and vice versa. Though relevant works in the literature point in the direction of BA44 and/or BA45 as the topography for tense and agreement features (see Section 2 above), my proposal consists in that neuroimaging analyses of three such languages as English, Spanish, and German in the way to be explained in Section 2.3.1 immediately below must result in a finer appreciation of neural activation as provoked by each of the two types of features independently of the other.

\subsubsection{Linguistic Explanation: the Neural Correlate of V-to-T Movement}

The concept of morphology that must be invoked in order to account for the prospective goal in $\left(2 \mathrm{~b}, \mathrm{~b}^{\prime}\right)$ is that according to which morphology is part of core syntax, independently of morphology being also an autonomous component in charge of regulating paradigms (see Section 2.2 above). The role played by morphology in the issue of the syntactic differentiation between tense features on the one hand and agreement features on the other hand, which is the one that matters now, centres around the presence or absence of a specific type of tense feature (as I argue in my own research in syntactic theory). In order to account for the latter, it is convenient to begin by recalling the highly-influential analysis of rich verbal morphology in the GB framework antedating Minimalism.

As is widely known, a mechanism that is postulated in GB syntax as affecting in a major way clausal architecture is $V$-to-T movement. In effect, V-to-T movement is defended by Roberts (1985), and above all by Pollock (1989), and also later by Belletti (1990), Chomsky (1991), or Lightfoot and Hornstein (1994), all of whom argue that the position of negation and also the position of frequency adverbs after the finite verb proves that languages like French, Spanish, or Italian are $\mathrm{V}$-to-T languages, that is languages where the finite verb raises to $\mathrm{T}$ in order to license its tense features and its agreement features, whereas English and Germanic languages in general are characterized as non-V-to-T languages - see the labelled bracketing structures in (3a) and (3b). Interestingly, German is initially considered to be V-to-T, and therefore a big exception within the Germanic family, though this position is reversed later in time (see immediately below).

(3) a. John always sings opera

a.' $\quad\left[\mathrm{TP} \mathrm{John}_{\mathrm{s}}\left[\mathrm{T}^{+}\right.\right.$pres. $\left[{ }_{\mathrm{vP}} \mathrm{t}_{\mathrm{s}}\left[\mathrm{v}^{\text {always }}\left[\mathrm{vsing}_{\mathrm{v}}\left[\mathrm{vP}_{\mathrm{v}}\right.\right.\right.\right.$ opera $\left.\left.\left.\left.]\right]\right]\right]\right]$ No V-to-T movement in English

b. Juan canta siempre opera

Juan sings always opera 


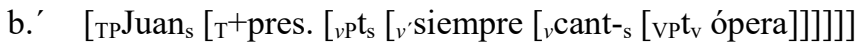

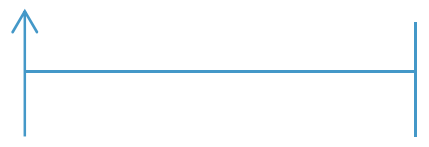

In a crucial way, the cause or trigger of V-to-T comes to be imputed in manifold works to rich tense and/or agreement morphemes (see among others Pollock 1989; Platzack and Holmberg 1989; Roberts 1993; Rohrbacher 1994, 1999; Vikner 1997) though the precise type of feature or feature combination does not seem to be identified. Incidentally, on the side of the neuroimaging literature, it must also be said that references to V-to-T do not abound at all (though see later in this Section).

Partly as a consequence of the failure to identify the trigger of V-to- $\mathrm{T}$ in the linguistic literature, an important part of this stops considering V-to-T (and headmovement in general) as a syntactic movement proper and starts analyzing it as a phonological mechanism, independent of core or narrow syntax. In Castillo (2014, 2016) I propose that V-to- $T$ in Romance languages and in old stages of Germanic languages has indeed a morphological cause, which appears to have gone unnoticed thus far, and which consists in the stem vowel morpheme, a subtype of tense morpheme. See the segmentation in (4) below, and its implementation on a finite verbal form in Spanish (5a), English (5b), and German (5c).

(4) root + stem vowel + tense/mood + agreement

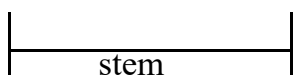

(5) a. nosotros llam- á- ba -mos ('we knocked/used to knock') (Spanish)

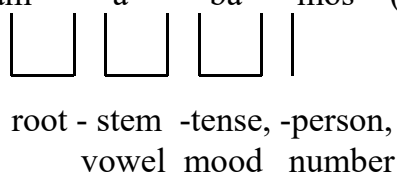

b. we knock- ed - $\varnothing$

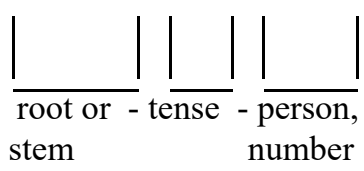

(English)

c. wir klopf- $\bigsqcup^{\mathrm{t}} \bigsqcup^{\text {-en }} \bigsqcup^{\text {('we knocked') }}$

(German)

$$
\begin{array}{ll}
\text { root or - tense } & \text {-person, } \\
\text { stem } & \text { number }
\end{array}
$$

This appears to solve the dilemma of a language like German, which has been revised in the recent literature as non-V-to-T (see e.g. Vikner 2001, 2005) but which appears to exhibit rich agreement morphology: under the approach that I have been 
able to develop, for German not to be a V-to-T language is no exception since it happens to lack the above-mentioned stem vowel morpheme. And this is the reason why it is so important to incorporate German as the intermediate case in the proposed tripartite analysis (see also below in the Section).

Incidentally, the Rich Agreement Hypothesis (or rather, the Rich Tense Hypothesis, on the approach that I defend) cannot be considered in absolute terms. In other words, for V-to-T to have a morphological cause from a formal point of view and also from a historical perspective (as I argue in my work on syntactic theory) does not preclude the existence of languages (like certain varieties of Swedish or Norwegian) which have scarce morphology, but whose verbs occupy the position to the left of frequency adverbs, and are therefore V-to-T languages. In a crucial way, such languages have relatively recently developed from non-V-to-T languages (canonical Swedish or Norwegian) and are apparently ceasing to be V2 languages: their becoming V-to-T is arguably a way of ensuring that the finite verb moves at all within sentence structure. ${ }^{9}$

Focusing then on the three languages that I would like to propose for the contrastive analysis in $\left(2 b^{\prime}\right)$, these would be, as suggested above, English, Spanish, and very importantly, German. According to the linguistic hypothesis that I defend, English has poor agreement features (i.e. few features distinguishing person and number) and poor tense features (i.e. tense features that do not include a stem vowel feature); Spanish has rich agreement features (i.e. a high number of features distinguishing person and number) and rich tense features (i.e. tense features that do include a stem vowel feature), and German has rich agreement features (i.e. a relatively high number of features distinguishing person and number) and poor tense features (i.e. tense features that do not include a stem vowel feature). The expectation is for the cited contrasts to have a reflection in the topography and/or in the timing of brain activation. Though it must be the case that any one contrast in neural activation that can possibly be obtained between the three languages is relevant for the goal in (2b), the specific contrast between the analysis of Spanish stimuli vs. German stimuli is crucial for the acknowledgement of the signature of V-to-T movement, since both languages exhibit rich agreement morphology (at least four different endings can be distinguished both for the present and for the past in the two languages), but only Spanish behaves as a V-to-T language.

As I observed above in this Section, references in the neuroimaging literature to the formalism or construct of syntactic theory that is V-to-T movement do not abound at all. There are actually studies that show that speakers do indeed recognize a linear sequence V-Adv as against another of the form Adv-V (see Lonzi and Luzatti 1993). However, the studies in question do not reach any conclusion as to

9 Also, I would like to observe that there are other approaches in the recent literature (see Biberauer and Roberts 2008) that have signaled rich tense as the cause of V-to-T: however, the idea of rich tense refers in Biberauer and Roberts (2008) to rich number of synthetic tenses, and this must presuppose that Germanic languages have always been non-V-to- $\mathrm{T}$ languages from their old periods, a view that does not seem to be tenable. 
the precise timing or specific brain area that is arguably activated whenever $\mathrm{V}$ is linearized before a frequency adverb.

The reader is referred to Appendix II for sample of the paradigm to be used in (prospective) neuroimaging experiments.

\section{A Proposal for the Analysis of Neural Activation Prior to the Processing of Tense Features and Agreement Features}

In the preceding Sections a proposal has been put forward that is directed at the identification of the neural signature of tense features and of agreement features in the process of computation of a sentence, an important assumption being that the processing of such features is part of the very initial stages of the overall processing of a sentence. The second part of the paper, which is restricted to the present Section, partially overlaps with the first part, since it deals with the stage in neural activity that presumably antedates the cited processing of tense features and agreement features between $\mathrm{T}, \mathrm{V}$, and $\mathrm{S}$ (ubject), namely phrase structure building of VP, and also crucially of TP. Within a general minimalist framework, such would be the initial stages in the computation of an ordinary sentence: that is, building up of VP, followed up by building up of TP, and subsequent processing of tense features and agreement features. Very simply put, the cited process consists in the following (see Chomsky 1995, 2000, 2001, 2004, et seq.). A VP containing $\mathrm{V}$ and (optionally) an object argument $(\mathrm{O})$ is constructed at the bottom of the tree, and on top of this a $v$ head is merged, into whose Spec position a subject argument $(\mathrm{S})$ is projected (see for instance the notation $t_{s}$ in $\left(3 \mathrm{a}^{\prime}\right)$ and $\left(3 \mathrm{~b}^{\prime}\right)$ above). In the simplest of cases, a sentence or TP will consist of the cited $v / \mathrm{VP}$, with a $\mathrm{T}$ head that is in turn merged on top of $v \mathrm{P}$. Corresponding Agree relations will ensure that both heads ( $\mathrm{T}$ and $v$ ) and phrases ( $\mathrm{S}$ and $\mathrm{O}$ ) have their features licensed against each other.

Now, I would like to introduce (6) as an initial general statement of the goal proposed here for future neuroimaging investigation. Such a goal actually invokes results already obtained in the very recent neuroimaging research, as acknowledged immediately below. The aim is to extend (6) so that more precise targets are established for potential new research.

(6) Identification of neural activation both in frontal areas and in temporal areas at the very first stages of the processing of a sentence.

Results in the neuroimaging research of the last ten to fifteen years reflect consensus, as has already been discussed in former Sections of the paper, that parts of LIFG constitute a core area of syntactic computing, and that BA44 and/or BA45 are the specific locations where tense features and agreement features appear to be processed. In a relevant way, parts of the temporal region, more specifically the left posterior middle and superior temporal gyrus (MTG/STG), have been analyzed as correlating with lexical knowledge (Hagoort 2005) or, in a framework closer to 
minimalist generative grammar, with phrase structure templates (Weber et al. 2016).

Establishing then a rough parallelism between the results obtained from neuroimaging research on the one hand, and the postulates of syntactic theory on the other, it appears to be the case that frontal brain areas are the ones involved in syntactic computation in the sense of valuation of features between heads and phrases (a relevant instance of this being the valuation of tense and agreement features) whereas MTG/STG would be the area where the structure of any given phrase is projected, that is the area where a head projects its complements and specifiers in accordance with its own lexical properties. In syntactic theory, the building up of phrase structure comes first, and then applies the valuation of features between the heads and phrases that are being projected. A major step forward in the neuroimaging literature is precisely the acknowledgment that the frontal region on the one hand and the temporal and parietal regions on the other are connected through both dorsal and ventral pathways (Meyer et al. 2012; Friederici 2012; Weber et al. 2016). A work like Friederici (2012) depicts in a clarifying way the neural circuit that very possibly corresponds to the processing of complex-syntax sentences (in the specific case illustrated by the author, structures where wh-movement applies) and it specifically postulates that neural activity begins in the above-cited temporal regions (where phrase structure is computed) and then it proceeds on to the frontal region (LIFG), an inverse connection between LIFG and temporal and parietal regions following in turn.

Now, the proposals that are put forward in this paper relate to the processing of sentences of the affirmative declarative type with a minimal number of constituents, that is sentences where a minimal number of feature valuation or Agree operations take place: (2) in the preceding Sections is a proposal about the identification of the neural signature of the processing of tense features and of agreement features, the brain area in question arguably being parts of LIFG; as for the proposal in (6), which is to be completed below, it is actually directed at acknowledging or verifying the first steps in the neural activation circuit that is described in e.g. Friederici (2012), a major condition being that the relevant linguistic material (or stimuli) must correspond to sentences with minimal syntactic relations. The goal is thus to verify the on-set time activation of the MTG/STG area, which would arguably correspond to the building up of the VP, and the on-set time activation of the LIFG area, which would correspond to the processing of tense features and of agreement features, with the prior projection of TP. Actually, the very construct that is a TP has full significance from the perspective adopted in this paper, as will be shown below.

In order to achieve the above, I propose to extend (6) in the way indicated:

(6) Identification of neural activation both in frontal areas and in temporal areas at the very first stages of the processing of a sentence:

a. Identification of neural activation in phrases that are not sentences (DPs, PPs, APs), with the inclusion of VPs.

b. Identification of neural activation in phrases that are sentences vs. phrases that are not sentences. 
c. Verification that the on-set time activation of MTG/STG is indeed prior to on-set time activation of LIFG for sentences, or rather the reverse.

The general goal as stated above in the Section is divided now into three tasks or proposals. Actually, (6c) is covered by (6b): however, I would like to present it this way since (6c) expresses in an explicit way dissent from the conclusions in the neuroimaging literature as to the initial topography of neural activity in the processing a sentence (see reference above to Friederici (2012)).

Starting with (6a), the aim is to monitor phrases that are not sentences, that is phrases that are not TPs (e.g. DPs, PPs, or APs), the expectation being that it is the temporo-parietal regions (MTG/STG) that will be activated. Incidentally, as specified in Appendix III at the end of the paper, the participants in the experiment are to be made aware before the experiment proper that the linguistic material they are about to read on the computer screen are not sentences. In an important way, VPs will be interspersed in the paradigm of stimuli, in order to see whether these phrases, which are ones that can become TPs (that is, actual sentences) are processed exactly like DPs, PPs, or APs, or not, that is if it could be the case that neural activity extends over more brain regions in the specific case of VPs. Among further relevant aspects to take into account is for the VP to contain a verb and an object or adjunct, but no subject (e.g. open the door / run to the park) since the inclusion of a subject would trigger in the brain/mind of the participants the condition of a sentence (that is the need for tense and agreement features to be licensed between $\mathrm{T}, \mathrm{V}$ and $\mathrm{S}$ ). On the other hand, the exclusion of a subject does not actually guarantee that the sentence-analysis in the brain/mind of the participants will be avoided, since such VPs as those cited above can be understood by the participants as imperative sentences. As regards non-VP phrases, attention must be paid to those containing objects proper (e.g. the arrest of John, jealous of him) and those containing adjunct constituents (e.g. the tall boys, this red book, good for you).

The central tasks are those in (6b) and (6c), since in these TPs are being monitored. The strategy that is proposed in order to be able to compare the processing of a TP-phrase and that of a non-TP phrase is to use very simple kinds of TP, more specifically SV sentences made up of two words, one word acting as the head of the DP subject and the other as the head of V. This way, the processing of a sequence like e.g. [John smiled] is to be contrasted with a DP containing also two words, like e.g. [long books], or a PP like [before March].

Now, in accord with the conclusions reached in the neuroimaging studies cited above in the Section, the expectation appears to be that temporo-parietal regions (MTG/STG) will be activated for all three kinds of phrases (TP, DP, PP) and that frontal areas in LIFG will be subsequently activated in the processing of TP. However, as stated in (6c), I propose to focus on verifying whether such is actually the case or whether the frontal area is activated from the very beginning whenever $\mathrm{SV}$ is processed. I would thus like to defend the hypothesis that it might not be the case that MTG/STG, where phrase structure of the initial VP is arguably represented, is activated first, and then from these the neural flow reaches LIFG, where the valuation of syntactic features takes place, more specifically tense features and agreement features (as made explicit in Friederici (2012)). Rather, the neurocognitive hypothesis that I would like to test is whether for the speaker to 
process a sentence means that the frontal area is immediately activated, the aim being to make available from the beginning an initial position, which supposedly correlates with the $\mathrm{D}$-feature that $\mathrm{T}$ must value, i.e. the feature associated with subject of predication (see Section 2.1 above) and which is also crucially the position typically occupied by the nominal that bears valued interpretable agreement features, which is at the core of the interplay between $\mathrm{T}, v / \mathrm{V}$ and $\mathrm{S}$, on a par with tense features. In other words, a nominal Subject is the constituent that values agreement features on the verb, and which also typically occupies initial position, more specifically initial position in neutral-order sequences. At least such is the case for the three languages proposed for the study-English, German, and Spanish-despite the fact that German is partially V2, and that Spanish allows quite frequently for V2 structures. The latter are of course circumstances that must be taken into account in the potential fMRi/MEG experiments that the present discussion aims to invoke.

Once again, the idea is that the processing of a phrase that is a TP is perhaps to demand the immediate activation of LIFG, or in any case a simultaneous activation of LIFG on the one hand, and of MTG/STG on the other. In contrast with the TP sequences, the non-TP sequences in the paradigm to present to the participants in the experiment will be expected to activate just MTG/STG, as with the material mentioned in relation to (6a). It must also be noted that it is possible that neural activity is restricted to the temporo-parietal areas for phrases like e.g. the AP very big, where very little feature valuation is needed, and that, in contrast, neural activity is registered further on in the region of LIFG for DPs like those books, which require number agreement valuation. The reader is referred to Appendix III for a sample of some of the stimuli.

\section{Summary of the Discussion}

Invoking general postulates of minimalist syntactic theory, and based upon neuroimaging research of the last two decades on the division of labour between frontal areas within LIFG and temporo-parietal areas (MTG/STG), the present paper proposes a line of investigation to be carried out in future fMRI and/or MEG experiments with an aim to fulfil specific goals relative to what are presumably the very initial stages of the processing of a sentence. Such stages appear to be the projection of VP and TP, and the immediate licensing of tense features and of agreement features. The goals proposed in the paper are cited below with the original numeration.

(2) Identification of the neural signature of tense features and agreement features in the process of computation of a sentence:

a. Verification that the neural correlate of tense features and agreement features as part of the building up of a sentence is distinct from the neural correlate of tense and agreement features as (mere) component elements of a morphological paradigm.

a.' Relevant methodology: Presentation of stimuli in the form of morphological paradigms vs. sentences proper. 
b. Verification that the neural correlate of tense features is distinct from that of agreement features.

b.' Relevant methodology: Contrastive analysis of three languages that behave differently in the licensing of tense features and agreement features.

(6) Identification of neural activation both in frontal areas and in temporal areas at the very first stages of the processing of a sentence:

a. Identification of neural activation in phrases that are not sentences (DPs, PPs, APs), with the inclusion of VPs.

b. Identification of neural activation in phrases that are sentences vs. phrases that are not sentences.

c. Verification that the on-set time activation of MTG/STG is indeed prior to on-set time activation of LIFG for sentences, or rather the reverse.

Positing the goals or tasks in (2) results from discussion about the connections between syntax and morphology, and specifically $(2 \mathrm{~b})$ is argued here to be feasible as based on the author's own explanation of the linguistic phenomenon of V-to-T movement. As for (6), the core issue that it invokes is whether the neural circuit that corresponds to the processing of a sentence begins with the activation of temporo-parietal areas and is then followed by activation of frontal areas (as concluded in various works in the neuroimaging literature), or whether activation of the frontal area is as a rule the initial stage whenever the processing of a sentence is involved (as hypothesized by the present author).

\section{Appendix I}

The goal described in (2a) in the core of the paper is coupled with a kind of methodology that is mainly based upon the way of presentation of linguistic stimuli in a potential fMRi and/or MEG experiment. A sample of this is illustrated in (I) vs. (II) below. In (I), two sets of stimuli (1 and 2) are presented in the form of a list or paradigm whereas in (II), two other sets (3 and 4) are presented in the form of sentences that the participant must complete. The features in the presentation of stimuli 3 and 4 that will arguably contribute to the perception of these as sentences proper are: the use of an adverb, the use of a period as a typical orthography symbol and, above all, the random alternation of person and number in subject position, and also the variation pronominal-full nominal.

Stimuli 1 differ from Stimuli 2 in the quantity of information provided on the screen relative to verbal paradigms. As for the contrasts between Stimuli 3 and 4, these relate to a different mode of presentation of a sentence proper. Stimuli 4 are just a variant to ensure that the participant in the experiment responds in the same way.

In a crucial way, in order to serve objective (2a), the result of the processing of Stimuli 1 and 2 must be contrasted with the result obtained from Stimuli 3 and 4 for each language separately. That is, the processing of the Spanish sequences in 1 and 2 are to be compared with the processing of the Spanish sequences in 3 and 4, and the same for English and German. 
(I)

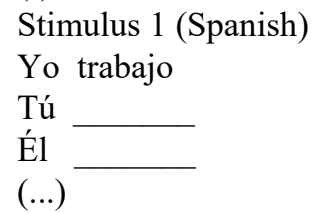

Stimulus 2 (Spanish)

Yo trabajo / Yo trabajé

Tú trabajas / Tú

Él trabaja / Él

(II)

Stimulus 3 (Spanish)

Él

TRABAJAR

María BAILAR ayer.

(...)

Stimulus 4 (Spanish)

Él / trabajar / hoy

María / bailar / ayer

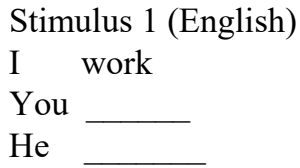

Stimulus 2 (English)

I work / I worked You work / You He works (...)
Stimulus 1 (German)

Ich arbeit

$\mathrm{Du}$

$\mathrm{Er}$

Stimulus 2 (German)

Ich arbeit / Ich arbeitete

Du arbeitest / Du
Stimulus 3 (English)

$\mathrm{He}$

$\overline{\text { WORK }}^{\text {today. }} \mathrm{Er}$ yesterday. Maria

Mary DANCE

Stimulus 3 (German) heute.

ARBEITEN gestern.
Stimulus 4 (English)
Stimulus 4 (German)
He / work / today
Er / arbeiten / heute
Mary / dance / yesterday Maria / tanzen / gestern

\section{Appendix II}

The linguistic stimuli to be used in order to fulfil the goal in (2b) coincide with those in (I) in Appendix I, though now the results are to be analyzed crosslinguistically. Thus, Stimuli 1 are directed at eliciting agreement features, while Stimuli 2 are directed at eliciting tense features, the aim being to compare the result of processing Stimulus 1 for Spanish with Stimulus 1 for English, and Stimulus 1 for German, and the same regarding Stimulus 2. This kind of paradigm would be a tool for identifying the signature of so-called V-to-T movement as discussed in the main text.

Stimulus 1 (Spanish)

Yo trabajo

Tú

Él

(...)

Stimulus 2 (Spanish)

Yo trabajo / Yo trabajé Tú trabajas / Tú

Él trabaja / Él
Stimulus 1 (English)

I work

You

$\mathrm{He}$

Stimulus 2 (English)

I work / I worked You work / You

He works (...)
Stimulus 1 (German)

Ich arbeit

$\mathrm{Du}$

Er

Stimulus 2 (German)

Ich arbeit / Ich arbeitete

Du arbeitest / Du 


\section{Appendix III}

The goal described in (6b) in the main text is central to the verification or otherwise the acknowledgment of the activation of frontal areas vs. temporoparietal areas as regards the processing of a simple sentence. Specifically, (6b) consists in analyzing the contrasts between phrases that are TPs (i.e. sentences) and phrases that are not TPs. As has been emphasized in the corresponding Section, in order for the two kinds to be comparable at all, it is necessary that the relevant sequences be very simple as regards number of lexemes per sequence, since this will also entail a small number of syntactic relations of Agree.

Below are presented four types of stimuli. A relevant strategy to employ consists in that, before presenting each set of stimuli, the participants must be informed about the semantics or interpretation of the sequences, namely that they refer to locations, or to object characterization... or otherwise that they answer the question 'What happened?', which is the one eliciting a TP or sentence. That is, the purpose is for the participants to concentrate on the meaning, and crucially to have them process the syntax in an unbiased way. The expectation is that very little or no activation of LIFG applies in 1-3, but mainly of temporal areas, whereas LIFG will be clearly activated in the processing of 4 , which activation will be arguably simultaneous with that of the temporal region.

Also very importantly, the subject speakers participating in the experiment are to be asked to judge whether the sequences are correct, a clue being that all the sequences are actually correct.

\begin{tabular}{|c|c|c|c|}
\hline $\begin{array}{l}\text { Stimulus } 1-4 \\
1 \text { Object characterization } \\
\text { (non-TP) }\end{array}$ & $\begin{array}{l}\text { (Spanish) } \\
\text { libro rojo } \\
\text { mesa grande } \\
\quad(\ldots)\end{array}$ & $\begin{array}{l}\text { (English) } \\
\text { red book } \\
\text { big table }\end{array}$ & $\begin{array}{l}(\text { German }) \\
\text { rotes Buch } \\
\text { großer Tisch }\end{array}$ \\
\hline $\begin{array}{l}2 \text { Locations } \\
\text { (non-TP) }\end{array}$ & $\begin{array}{l}\text { en Australia } \\
\text { en el tren } \\
(\ldots)\end{array}$ & $\begin{array}{l}\text { in Australia } \\
\text { on the train }\end{array}$ & $\begin{array}{l}\text { in Australien } \\
\text { im Zung }\end{array}$ \\
\hline $\begin{array}{l}3 \text { Object possession } \\
\text { (non-TP) }\end{array}$ & $\begin{array}{l}\text { mi libro } \\
\text { tu ordenador } \\
(\ldots)\end{array}$ & $\begin{array}{l}\text { my book } \\
\text { your computer }\end{array}$ & $\begin{array}{l}\text { mein Buch } \\
\text { ihren Computer }\end{array}$ \\
\hline $\begin{array}{l}4 \text { Answers to the question: } \\
\text { What happened? } \\
\text { (TP) }\end{array}$ & $\begin{array}{l}\text { Yo bailé } \\
\text { María esperó } \\
(\ldots)\end{array}$ & $\begin{array}{l}\text { I danced } \\
\text { Mary waited }\end{array}$ & $\begin{array}{l}\text { Ich tanzte } \\
\text { Maria wartete }\end{array}$ \\
\hline
\end{tabular}

\section{References}

Belletti, Adriana (1990). Generalized Verb Movement: Aspects of Verb Syntax. Turin: Rosenberg and Sellier. 
Belletti, Adriana, ed. (2004). Structures and Beyond. Oxford and New York: Oxford University Press.

Biberauer, Theresa and Ian Roberts (2008). Cascading parameter changes: Internallydriven change in Middle and Early Modern English. In E. Thórhallur, ed., 79-113.

Castillo, Concha (2014). On the trigger of V-to-T movement. Miscelánea: A Journal of English and American Studies 49: 29-51.

Castillo, Concha (2016). The morphological trigger of V-to-T: The case of Old English. Studia Anglica Posnaniensia 51: 5-51.

Chomsky, Noam (1981). Lectures on Government and Binding. The Pisa Lectures. Dordrecht: Foris.

Chomsky, Noam (1991). Some notes on economy of derivation and representations. In Robert Freidin, ed., 417-454.

Chomsky, Noam (1995). The Minimalist Program. Cambridge, Mass.: MIT Press.

Chomsky, Noam (2000). Minimalist inquiries: The framework. In Roger Martin, David Michaels and Juan Uriagereka, eds., 89-156.

Chomsky, Noam (2001). Derivation by phase. In Michael Kenstowicz, ed., 1-52.

Chomsky, Noam (2004). Beyond explanatory adequacy. In Adriana Belletti, ed., 104-131.

Chomsky, Noam (2005). Three factors in the language design. Linguistic Inquiry 36: 1-22.

Chomsky, Noam (2008). On phases. In Carlos P. Otero, Robert Freidin and María-Luisa Zubizarreta, eds., 133-166.

Eythórsson, pórhallur, ed. (2008). Grammatical Change and Linguistic Theory: The Rosendal Papers. Amsterdam: John Benjamins.

Finocchiaro, Chiara, Gianpaolo Basso, Alessia Giovenzana and Alfonso Caramazza (2010). Morphological complexity reveals verb-specific prefrontal engagement. Journal of Neurolinguistics 23: 553-563.

Freidin, Robert, ed. (1991). Principles and Parameters in Comparative Grammar. Cambridge, Mass.: MIT Press.

Friederici, Angela D. (2011). The brain basis of language processing. From structure to function. Physiological Reviews 91: 1357-1392.

Friederici, Angela D. (2012). The cortical language circuit: From auditory perception to sentence comprehension. Trends in Cognitive Sciences 16: 262-268.

Guéron, Jacqueline and Jacqueline Lecarme, eds. (2004). The Syntax of Time. Cambridge, Mass.: MIT Press.

Haegeman, Liliane, ed. (1997). The New Comparative Syntax. London: Longman.

Hagoort, Peter (2005). On Broca, brain, and binding: A new framework. Trends in Cognitive Sciences 9: 416-423.

Jackendoff, Ray (1977). X'-Syntax. A Study of Phrase Structure. Linguistic Inquiry Monograph 2. Cambridge, Mass: MIT Press.

Karimi, Simin, Vida Samiian and Wendy K. Wilkins, eds. (2007). Phrasal and Clausal Architecture: Syntactic Derivation and Interpretation. In Honor of Joseph E. Emonds. Amsterdam: John Benjamins.

Kenstowicz, Michael, ed. (2001). Ken Hale: A Life in Language. Cambridge, Mass.: MIT Press.

Kielar, Aneta, Lisa Milman, Borna Bonakdarpour and Cynthia K. Thompson (2011). Neural correlates of covert and overt production of tense and agreement morphology: Evidence from fMRI. Journal of Neurolinguistics 24: 183-201. 
van der Lely, Heather K.J. and Steven Pinker (2014). The biological basis of language: Insight from developmental grammatical impairments. Trends in Cognitive Sciences 18: 586-595.

Lightfoot David and Norbert Hornstein, eds. (1994). Verb movement. Cambridge: Cambridge University Press.

Lonzi, Lidia and Claudio Luzzatti (1993). Relevance of adverb distribution for the analysis of sentence representation in agrammatic patients. Brain Language 45: 306-317.

Martin, Roger, David Michaels and Juan Uriagereka, eds. (2000) Step by Step: Essays on Minimalist Syntax in Honor of Howard Lasnik. Cambridge, Mass.: MIT Press.

Meyer, Lars, Jonas Obleser, Alfred Anwander and Angela D. Friederici (2012). Linking ordering in Broca's area to storage in left temporo-parietal regions: The case of sentence processing. Neuroimage 62: 1987-1898.

Opitz, Bertram and Angela D. Friederici (2004). Brain correlates of language learning: The neuronal dissociation of rule-based versus similarity-based learning. Journal of Neuroscience 24: 8436-8440.

Otero, Carlos P., Robert Freidin and María-Luisa Zubizarreta, eds. (2008). Foundational Issues in Linguistics. Cambridge, Mass.: MIT Press.

Pesetsky, David and Esther Torrego (2001). T-to-C movement: Causes and consequences. In Michael Kenstowicz, ed., 355-426.

Pesetsky, David and Esther Torrego (2004). Tense, Case, and the nature of syntactic categories. In Jacqueline Guéron and Jacqueline Lecarme, eds., 495-538.

Pesetsky, David and Esther Torrego (2007). The syntax of valuation and the interpretability of features. In Simin Karimi, Vida Samiian, and Wendy K. Wilkins, eds., 262-294.

Petersson, Karl Magnus and Peter Hagoort (2012). The neurobiology of syntax: Beyond string sets. Philosophical Transactions of the Royal Society 367: 1971-1983.

Platzack, Christer and Anders Holmberg (1989) .The role of AGR and finiteness. Working Papers in Scandinavian Syntax 43: 51-76.

Pollock, Jean-Yves (1989). Verb-movement, Universal Grammar, and the structure of IP. Linguistic Inquiry 20: 365-424.

Roberts, Ian (1985). Agreement parameters and the development of English modal auxiliaries. Natural Language and Linguistic Theory 3: 21-58.

Roberts, Ian (1993). Verbs and Diachronic Syntax. Dordrecht: Kluwer.

Rohrbacher, Bernhard (1994). The Germanic Languages and the Full Paradigm: A Theory of $V$ to I Raising. Amherst, Mass.: Univ. of Massachusetts dissertation.

Rohrbacher, Bernhard (1999). Morphology-Driven Syntax. A Theory of V to I Raising and Pro-Drop. Amsterdam: John Benjamins.

Sahin, Ned T., Steven Pinker, Sydney S. Cash, Donald Schomer and Eric Halgren (2009). Sequential processing of lexical, grammatical, and phonological information within Broca's area. Science 326: 445-449.

Shapiro, Kevin A., Lauren R. Moo and Alfonso Caramazza (2012). Neural specificity for grammatical operations is revealed by content-independent fMR adaptation. Frontiers in Psychology 3: 26.

Thórhallur Eythórsson (2008). Grammatical Change and Linguistic Theory. The Rosendal Papers. Amsterdam: John Benjamins.

Vikner, Sven (1997). V-to-I movement and inflection for person in all tenses. In Liliane Haegeman, ed., 189-213.

Vikner, Sven (2001). Verb movement variation in Germanic and Optimality Theory. Ms., University of Tübingen. 
Vikner, Sven (2005). Immobile complex verbs in Germanic. Journal of Comparative Germanic Linguistics 8: 83-115.

Weber, Kirsten, Morten H. Christiansen, Karl Magnus, Petersson, Peter Indefrey and Peter Hagoort (2016). fMRI syntactic and lexical repetition effects reveal the initial stages of learning a new language. The Journal of Neuroscience 36: 6872-6880.

Yokoyama, Satoru, Tadao Miyamoto, Jorge Riera, Jungho Kim, Yuko Akitsuki et al. (2006). Cortical mechanisms involved in the processing of verbs: An fMRI study. Journal of Cognitive Neuroscience 18: 1304-1313. 